\title{
Improving IT project governance: A reflective analysis based on critical systems heuristics
}

\section{David Johnstone}

Victoria University of Wellington

david.johnstone@vuw.ac.nz

Mary Tate

Queensland University of Technology

\section{Abstract}

IT project governance involves establishing authority structures, policies and mechanisms for IT projects. However, the way governance arrangements are implemented can sometimes exclude or marginalise important stakeholders. In this paper, we use critical systems thinking, and the notions of boundary critique and entrenched structural conflict, to inform a critical reanalysis of a case study where the governance proved relatively ineffective. We use the 'twelve questions' from the critical systems heuristics (CSH) approach to diagnose problems with governance arrangements and suggest solutions. Based on this, we suggest the CSH approach has theoretical and practical efficacy for improving IT project governance in general.

Keywords: IT project governance; paradigms; critical systems heuristics; boundary critique

"Nothing about us without us" (anon)1

\section{Introduction}

IT projects typically involve a range of stakeholder groups. Adapting Freeman's (1984) original, generic definition, a project stakeholder is any group or individual who can affect, or is affected by, the conduct and outcomes of the project (Mitchell, Agle, \& Wood, 1997). Different stakeholder interests generate different agendas, and stakeholder conflict within IT projects is common because "...independent people must work together to achieve multiple objectives in an environment of flux, ambiguity, and scarce resources." (Hammer, 1997, p.165). While it is true that many published guidelines on the management of organisational projects, such as the Project Management Body of Knowledge (PM-BOK), The Open Group Architecture Forum (TOGAF) and PRINCE2 now have more comprehensive sections on stakeholder management and engagement, there is still a sense that conflict should be resolved by dealing with troublesome stakeholders, rather than seeing the conflict as potentially constructive (Richet, Ngwenyama, \& Rowe, 2016). We argue, following Roberts, Cheney, and Sweeney (2002), that a broader, more nuanced understanding of stakeholders' perspectives is required to address their concerns, incorporate their views into the decision-making process, and reduce damaging project conflict. This means examining the framework under which project performance monitoring, decision-making, and managerial action takes place. That is the role of project governance (Muller, 2009; PMI, 2013; Turner, 2009).

This has already been recognised at a corporate governance level: "The critical governance tasks ... are to ensure effective negotiations, coordination, cooperation, and conflict resolution to maximize and distribute the joint gains among multiple parties of interest" (Kochan \& Rubinstein, 2000, p. 370). We examine how this can be enacted at an IT project governance level.

\footnotetext{
${ }_{1}^{1}$ This is a slogan and credo that originated in disability rights groups, and has subsequently been adopted by other interest groups to communicate the idea that no policy should be decided by any representative without the full and direct participation of members of the group(s) affected by that policy. (http://en.wikipedia.org/wiki/Nothing_About_Us_Without_Us)
} 
We applied Ulrich's (1983) Critical Systems Heuristics (CSH), employing boundary critique and his 'twelve questions' (Ulrich \& Reynolds, 2010) to perform a critical analysis of the governance of an IT project. We emphasise that this project was not conducted from its inception as critical research (Myers \& Klein, 2011) per se. Our contributions are to demonstrate how $\mathrm{CSH}$ can be used as a reflective and diagnostic tool to generate fresh insights in an IT project context, and to suggest how critical principles can be incorporated into our understanding of IT project governance. To our knowledge, this is the first study to offer a critical analysis of IT project governance.

$\mathrm{CSH}$ is based on critical systems approaches used by social scientists for framing, analysing and intervening in complex social situations involving multiple, interconnected factors that are frequently characterised by significant conflict between stakeholder groups. The notion of boundary critique, and the application of CSH questioning, are tightly linked: "In CSH, the process of questioning boundary judgements is crucial” (Ulrich \& Reynolds, 2010, p.263).

IT projects can be characterised as complex social situations involving multiple stakeholder groups, sometimes with incompatible perceptions of success (Davis, 2014), goals and values. IT project governance can be characterised as a framework for setting and managing boundaries and interactions between various stakeholder groups in which project management is carried out. We therefore propose $\mathrm{CSH}$ as a technique for informing IT project governance design.

Our research questions are: RQ1) What insights can $\mathrm{CSH}$, as a diagnostic tool, contribute to our understanding of IT project governance in this case study? RQ2) How can CSH be used effectively as a tool for improving IT project governance?

The rest of this paper is structured as follows. We offer a literature review, then we introduce the original case context and the methodology used in this study. Next we present the results, followed by a discussion and a conclusion.

\section{Critical Systems Heuristics and Boundary Critique}

This section introduces a brief background to $\mathrm{CSH}$, boundary setting, boundary critique, and CSH literature.

\subsection{Boundaries, social systems and conflict}

Analysis of boundaries in social systems begins with the premise that in complex social systems there are a wide range of interconnected forces undergoing continuous interaction; everything is directly or indirectly connected to everything else. "However, you can't have a God's eye view...so there are inevitable limits to understanding, and it is those limits that we call boundaries" (Midgley \& Richardson, 2007, p.167). Boundaries start out as cognitive boundaries; as both Midgley (1992) and Ulrich (2000) point out, internal perceptions of the boundaries of a problem or situation are a general cognitive prerequisite for identifying and understanding a system of concern to the respective decision-maker. In social systems, boundaries may be conceptual or social constructs; that is, they are perceived, negotiated or created by the participants in the system, rather than being 'real' characteristics that are present in the environment (Churchman, 1970). Boundaries "mark the [real or perceived] inclusion or exclusion of stakeholders, people and issues. They demarcate what is relevant to an analysis" (Midgley \& Richardson, 2007, p.172), but they start as beliefs about the importance or legitimacy of various groups.

In many social situations, there may be multiple, sometimes conflicting, views of the appropriate boundaries for inclusion and exclusion of issues and stakeholders. This type of mismatch is conceptualised in Figure 1 (Midgley, 1992). The inner ellipse represents a boundary judgment (A) by one group, and the next ellipse is a boundary judgment (B) by a second group. Midgley called the area in between these two boundaries the marginal area. He suggested that each of the boundaries reflects a value judgement about inclusions and exclusions. When these value judgements are not shared between the stakeholder groups, 
damaging conflicts can arise. Further, if the value conflicts are not recognised and addressed, they can 'stabilise' and perpetuate over longer periods of time, so that although immediate conflict situations may be resolved, divisions between stakeholder groups can continue for an extended period, generating further instances of conflict (Midgley \& Pinzon, 2011).

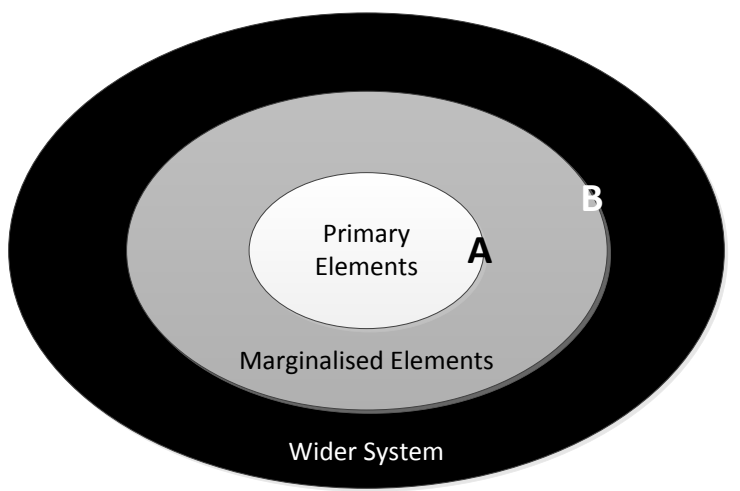

Figure 1. Marginalisation through boundary setting (adapted from Midgley, 1992).

\subsection{Boundary Critique using Critical Systems Heuristics}

Ulrich (1987) developed a set of questions which he called 'critical systems heuristics' (CSH). These questions invite stakeholder participants to reflect on what they believe the current situation is, and what, in their view, it ought to be. The questions focus on four areas: motivation, control, expertise, and legitimacy. Motivation focuses on the purpose and beneficiaries of the system and whose interests are being served. Control establishes who has decision-making authority and what resources they have at their disposal. Expertise describes what forms of knowledge are necessary, and where that knowledge resides. Legitimacy considers the worldview and potential sources of oppression inherent in a social system. Ulrich suggests that the CSH approach can be used as a reflective and diagnostic tool by comparing the 'Descriptive Mapping' of a situation (also called the 'Is' analysis) with the 'Ideal Mapping' (identifying the 'Ought') (Ulrich \& Reynolds, 2010, p.266). We have adapted Ulrich's twelve questions as 'was' and 'ought' questions for coding and reflecting, respectively, on the case data. These are listed in Table 1.

\begin{tabular}{|c|c|}
\hline $\begin{array}{l}\text { Focussing } \\
\text { question }\end{array}$ & Questions for coding the case data \\
\hline $\begin{array}{l}\text { MOTIVATION: } \\
\text { Focus on the } \\
\text { beneficiary }\end{array}$ & $\begin{array}{l}\text { 1. Who was/ought to have been the beneficiary of the project? } \\
\text { 2. What was/ought to have been the purpose of the project? } \\
\text { 3. What was/ought to have been the project's measure of success? }\end{array}$ \\
\hline $\begin{array}{l}\text { AUTHORITY: } \\
\text { Focus on the } \\
\text { decision-maker }\end{array}$ & $\begin{array}{l}\text { 4. Who was/ought to have been the decision-maker that controlled the } \\
\text { conditions for project success? } \\
\text { 5. What resources were/ought to have been controlled by the decision- } \\
\text { maker? } \\
\text { 6. What resources were/ought to have been outside the control of the } \\
\text { decision-maker? }\end{array}$ \\
\hline $\begin{array}{l}\text { KNOWLEDGE: } \\
\text { Focus on the expert } \\
\text { / professional }\end{array}$ & $\begin{array}{l}\text { 7. Who did/ought to have provided the relevant knowledge and skills? } \\
\text { 8. What were/ought to have been the necessary knowledge and skills? } \\
\text { 9. What were/ought to have been regarded as assurances of successful } \\
\text { implementation? }\end{array}$ \\
\hline
\end{tabular}




\begin{tabular}{|l|l|}
\hline $\begin{array}{l}\text { Focussing } \\
\text { question }\end{array}$ & Questions for coding the case data \\
\hline $\begin{array}{l}\text { LEGITIMATION: } \\
\begin{array}{l}\text { Focus on those } \\
\text { affected, but not } \\
\text { involved }\end{array}\end{array}$ & $\begin{array}{l}\text { 10. Who was/ought to have been representing the interests of those } \\
\text { negatively affected by, but not involved with the project? }\end{array}$ \\
$\begin{array}{l}\text { 11. What were/ought to have been the opportunities for the interests of } \\
\text { those negatively affected to have expression and freedom from the } \\
\text { worldview of the project? }\end{array}$ \\
$\begin{array}{l}\text { 12. What space was/ought to have been available for reconciling } \\
\text { differing worldviews regarding the project among those involved and } \\
\text { affected? }\end{array}$ \\
\hline
\end{tabular}

Table 1. Twelve focussing questions for coding and analysing the case data.

The CSH method falls generally within the stream of critical systems thinking (CST) research, which has many variants and has been the subject of intense methodological and paradigmatic debates (Jackson, 2003; Midgley, 1997; Ulrich, 2012). We remain largely agnostic in these discussions; in this, we align ourselves with the recent thinking of Ulrich (2012) himself, who lamented that "the discussion about CST has remained largely an insider discussion" (p. 1233). Ulrich (2012) emphasised that his method is intended to be used and to be usable and therein "resides the basic idea and value of 'critical' systems thinking: it can support reflective practice with special regard to contextual selectivity" (p.1233). Nevertheless, we acknowledge one criticism which may affect the practical efficacy of the method; that it is utopian (Flood and Jackson, 1991), and is impractical when there is a clear power imbalance: "why should the involved bother to take account of the views and interests of those who are affected but not involved?" (Jackson, 2003, p 227). We aim to explore the practical value of CSH for informing IT project governance arrangements, rather than contributing to the theoretical and paradigmatic debates.

\subsection{IT Project Governance and IT Project Management}

The concepts of governance and management, within an organisational context, are tightly linked, though distinct in purpose. "The governance system defines the structures used by the organization, allocates rights and responsibilities within those structures, and requires assurance that management is operating effectively and properly within the defined structures. The role of management is to manage the organization within the framework defined by the governance system; this applies particularly to the governance and management of projects." (Too \& Weaver, 2014, p.1385, emphasis added). More specific conceptualisations of project governance, however, continue to offer a diversity of opinion (Biesenthal \& Wilden, 2014). Nevertheless, there is some commonality across most definitions of project governance arrangements. These include the allocation of decision-making authority and responsibility (e.g. Pinto, 2014; Too \& Weaver, 2014); development of policies that guide and constrain decision-making (e.g. Klakegg, Williams, Magnussen, \& Glasspool, 2008); and implementation of mechanisms that support decision-making and implementation, including processes, procedures, and methodologies (e.g. those described in practitioner guidelines such as the PM-BOK). This provides a coherent definition of IT project governance (ITPG), where these arrangements "...specify why, where and when decisions are made (policy), who should make them (authority), and how they should be made and implemented (mechanisms)." (Johnstone, Huff, \& Hope, 2006).

Project governance may operate at different levels within the organisation, depending on the project context (Bekker, 2014). For example, Biesenthal and Wilden (2014) identified three distinct levels: the organisational level (overseeing portfolio direction, project sponsorship, and high-level reporting), the project management office level (overseeing portfolio/ programme management, project evaluation and prioritisation), and project level (overseeing project management, delivery, objectives, expectations and outcomes). However, how these project governance levels are realised in practice may vary considerably across different 
organisations. A commonly used authority structure for ITPG at the project level is a project steering committee (Van Grembergen \& De Haes, 2009), which is responsible not only for project oversight, but high-level decision-making where issues that could not be resolved by the project manager were escalated (Jiang, Klein, \& Carr, 2002).

\section{Method}

For this study, we analysed previously collected case data using a boundary critique lens and abductive reasoning. We briefly describe the method used to capture the original case data, and the method used to perform the analysis for this study.

\subsection{The method used for the original case study research}

Originally, the research initiative employed a case research method (Eisenhardt, 1989) investigating IT project governance and stakeholder conflict (Johnstone, 2010). Data was collected across five cases, where each case represented recently completed IT project(s) for a different organisation. Semi-structured interviews were conducted with key participants involved with the IT project for each case. Archival material was used to augment and triangulate the interview data. This paper is based on data collected from one of these cases.

\subsection{The method used for this study}

We started with an abductive approach based on a critical reading of the original case transcripts to arrive at some initial propositions which we developed based on critical systems thinking literature. The viewpoint represented in the analysis is therefore that of the research team, adopting a critical stance with regard to the original case data. Abductive reasoning can re-examine previously observed phenomena: Abduction...works through interpreting or recontextualizing individual phenomena within a contextual framework, and aims to understand something in a new way, from the perspective of a new conceptual framework" (Kovács \& Spens, 2005, p.138). Abduction can be used to link existing theory to case analysis by creating "patterns of expectation" (propositions) which can be confirmed, or disconfirmed, by the detailed case data (Evers \& Echo, 2006). Our high-level propositions were that some stakeholder groups were marginalised, the project governance arrangements failed to adequately address this, and project conflict ensued. We asked ourselves "if one stakeholder group were genuinely marginalised, or felt marginalised, in this project, how well would this explain the case data?" This informed the 'is' perspective in the analysis.

To do the detailed analysis, initially, the entire set of transcripts for the original case, and all relevant archival material was re-read. We then used pattern matching (Campbell, 1966; Yin, 2013). A pattern is a characteristic of qualitative data analysis that focuses on patterns of relationships between variables in a holistic way. Patterns can be derived from literature, theory, or even reflection and experience (Almutairi, Gardner, \& McCarthy, 2014). In our case, the twelve CSH questions formed the 'patterns'. For example, for the questions associated with authority, we would scan for a description of a stakeholder group (e.g. 'Finance', 'Head Office', 'frontline staff') in combination with terms associated with authority such as 'decision', 'control', 'authority' 'resources' or their synonyms. Where multiple informants commented on the same issue, we compared data across informants to understand the convergence or divergence between their viewpoints. This analysis was then compared with our initial expectations and high-level propositions to see if the evidence supported the assertions (Evers \& Echo, 2006).

Following that, we asked "if the IT project governance arrangements had been configured differently, and more inclusively, what might the project have looked like?" This formed the 'ought' perspective. We note we were not able to perform a direct intervention in the project in question. However, the 'ought' perspective from the CSH questions provided important insights into the type of interventions that could usefully have been carried out, and yielded lessons for future IT project governance arrangements. 


\section{The Case Background}

\subsection{The Organisation and the Project ${ }^{2}$}

The government organisation that established the context for the project is responsible for providing emergency services on a national basis, involving trained professionals who carry out the frontline duties. They are operationally managed through stations geographically dispersed throughout the country, and are co-ordinated hierarchically through districts, then regions, and finally the centrally-located Head Office (HO). The organisation had a considerable investment in the equipment (assets) required to carry out the emergency services, most of which was located on specialist vehicles or housed in the stations. These assets had to be managed both physically and financially. Each station was responsible for regular maintenance checks and repairs of their equipment, using their own asset management system. Well-maintained equipment was critical to front-line personnel safety and job effectiveness.

Ten years earlier, as part of controversial economic reforms, a businessman with no prior experience in emergency services was appointed CEO of the organisation. Efficiencies were sought through cost reduction, primarily through reduction of staff and equipment, which caused acrimony among frontline staff, who saw it as a threat to their professionalism, safety and ability to perform effectively. There was extensive conflict at the time, culminating in national strike action. The experiment did not last long, the CEO was removed, and the 'efficiencies' largely reversed, but the memory of negative emotions and conflict between HO and the stations regarding equipment (assets) remained very strong.

The project currently in question formed part of the roll-out of a new ERP system. The first module, a financial management information system (FMIS), had been installed successfully. The implementation of the second ERP module - an asset management information system (AMIS) - was more problematic. The manual systems struggled to provide the financial data required by the Finance Department ('Finance') at HO. The new AMIS system was meant to standardise both physical and financial asset management electronically, from the station level through to the national level.

Following a similar structure to the previous ERP module, governance was established for the implementation of the AMIS system. The HO Executive Team, comprising the Chief Executive Officer (CEO), Chief Information Officer (CIO), Chief Financial Officer (CFO) and other organisational executives, assumed responsibility for project governance at the organisation level. A key role of the Executive Team, from a governance perspective, is establishing and allocating the membership of the Project Steering Committee (PSC). PSC membership for both the FMIS and AMIS projects included mostly the same people, mostly from HO, including the $\mathrm{CIO}$ and a strong representation from Finance (who were seen by $\mathrm{HO}$ as the primary ERP client). The PSC hired external consultants for two key roles: the project manager and a quality assurance (QA) consultant, who were both added to the PSC.

There was little by way of policy set by the Executive Team, leaving the PSC to act relatively autonomously. Despite occasional reporting to the Executive Team, there were no formal mechanisms available (beyond the PSC) to resolve the issues that ensued with AMIS. The PSC met once a month, being responsible for ITPG at the project level. They delegated extensive decision-making authority to the project manager, who had responsibility for day-to-day management regarding the conduct of the project, delivery of outcomes, allocation of resources, and stakeholder management. The PSC had oversight and final responsibility for these functions and received regular status reports from the project manager. They also got involved directly in decision-making from time to time, when they were unhappy with the performance of the project manager. The only other non-HO PSC member was a regional manager, co-opted onto the PSC only after problems with AMIS appeared, because of his

\footnotetext{
2 The project names and position titles have been altered to help preserve anonymity.
} 
knowledge of the business processes in the organisation at the station, district and regional levels. He was the only member of the PSC with any operational, frontline experience.

\subsection{The Research Participants}

A brief description of those interviewed is provided in Table 2. There were two project managers externally contracted for the AMIS project, one for the early part of the project, where the majority of events related to this paper occurred, and her replacement for the latter part of the project. Unfortunately, the original AMIS project manager had left the country at the time of interviewing, while the replacement did not wish to be interviewed.

\begin{tabular}{|c|c|c|}
\hline Interviewee Position & $\begin{array}{l}\text { IT Project } \\
\text { Governance Body } \\
\text { Membership }\end{array}$ & $\begin{array}{l}\text { Responsibility and Stakeholder } \\
\text { Representation }\end{array}$ \\
\hline $\begin{array}{l}\text { Chief Information Officer } \\
\text { (CIO) }\end{array}$ & $\begin{array}{l}\text { HO Executive Team; } \\
\text { Project Steering } \\
\text { Committee (AMIS) } \\
\end{array}$ & $\begin{array}{l}\text { Executive Team representative and the } \\
\text { most senior manager of the IT } \\
\text { Department }\end{array}$ \\
\hline National Finance Manager & $\begin{array}{l}\text { Project Steering } \\
\text { Committee (AMIS) }\end{array}$ & $\begin{array}{l}\text { Second most senior representative of } \\
\text { the Finance Department (after the } \\
\text { CFO), also from HO }\end{array}$ \\
\hline $\begin{array}{l}\text { Senior Vendor Consultant - } \\
\text { Project Team (AMIS) }\end{array}$ & [none] & Responsibility for client management \\
\hline QA Consultant & $\begin{array}{l}\text { Project Steering } \\
\text { Committee (AMIS) }\end{array}$ & $\begin{array}{l}\text { Independent advisor reporting on both } \\
\text { system and process quality }\end{array}$ \\
\hline Regional Manager & $\begin{array}{l}\text { Project Steering } \\
\text { Committee (AMIS) }\end{array}$ & $\begin{array}{l}\text { Co-opted later onto the PSC for his asset } \\
\text { knowledge at the station level }\end{array}$ \\
\hline
\end{tabular}

Table 2. Case study interviewees.

\subsection{The Events}

The AMIS PSC agreed from the outset that a critical pre-requisite for an integrated, national asset management module was to conduct a thorough inventory and classification of the organisations' assets. The intention was to collect the data from stations and vehicles across the country, and use this to populate the new AMIS database. Finance already possessed highlevel financial data, but was unable to break it down. Consequently, Finance developed a classification system for the assets, and contracted an external firm to work with the organisation and visit each station across the country to collect the necessary data. In practice, this meant a team of two (one contractor, and one frontline staff member from the relevant district) would arrive at a station and ask the personnel there to strip down the vehicles of equipment, as well as note what was in the station, and the collection team would record the information. This was a time-consuming, unpopular exercise: “...we were pushing for accuracy, [and so frontline staff] had to go off and check their assets ... it's just an extra burden for them. ... [capturing] information that is of importance and value to the Head Office people who make these policy decisions. ... but not to the people on the outside who are actually going to do all the work." [CIO]

The collection took longer than expected; it was not seen as a high priority at station level. Furthermore, feedback from the data collection teams suggested Finance's classification system for the asset information was poorly designed, and they struggled to determine how the asset information was to be recorded using it. At the end of the exercise, the station-level data was aggregated and compared with HO's national figures. It was clear the collected data was far from accurate, leaving the PSC puzzled as to why the collection process failed: "All the processes were there to make sure we got the best data that we could....So, in theory, we should have got full cooperation and really good data out of it." [National Finance Manager] 
Consequently, the PSC decided to repeat the data collection process, this time with an asset classification scheme that was revised with the help of the Regional Manager on the PSC, who called on his frontline experience and knowledge. However, resistance was still an issue as many stations were now even more reluctant to cooperate. The collected asset data, although more accurate than before, was still regarded by the PSC as inadequate.

After considerable debate within the PSC, despite a likely budget and schedule blowout for the AMIS project, a third round of data collection was conducted. The PSC also fired the AMIS project manager at this point. The resulting aggregated figures had improved again, though many on the PSC were still unhappy with the discrepancies. After considerable debate, the PSC decided this time they would not pursue a fourth attempt. As the CIO was to observe, there was a "collective weariness" over the issue within the PSC, and they were unsure how frontline Operations staff would react to yet another round of data collection.

\section{Results}

Based on the analysis of the re-coded data, responses to the 12 questions adapted from Ulrich (1987) are presented. The information provided was sourced from two or more participants. No factual inconsistencies between participants were apparent.

\subsection{CSH Analysis}

We employ the 12 questions as an analytical tool in order to make sense of the situation of interest. In particular, we aim to identify the differences between stakeholder views, representing these multiple perspectives as boundary judgements.

\subsection{Sources of Motivation}

\subsubsection{Question 1: Who ought to have been/was the beneficiary of the project?}

The project was proposed by Finance to improve their ability to manage asset financial information. This was supported by the executive because this improved capability would also support the organisation's strategic objectives to utilise government funding more effectively. Because AMIS would standardise physical asset management electronically, it was assumed (by HO generally, and Finance specifically) that station managers would also benefit. However, station staff did not see themselves as beneficiaries of AMIS, as they already had manual systems of their own, which generally worked well at a local level, and issues around data aggregation at higher levels did not affect them: “...it [asset classification] would just be done late ... and skimpily. We would get figures down that were not trustworthy. It became, to [the stations], a low priority task." [CIO]. A gap exists between $\mathrm{HO}$, who believed the stations will benefit, and the stations, who felt they would not only fail to benefit, but would incur additional work for someone else's benefit. Frontline staff were responsible for initially recording and classifying the physical assets, and for updating the system on an ongoing basis, and so ought to have received some reward or recognition as an incentive, although how this would work in practice is unclear.

\subsubsection{Question 2: What ought to have been/was the purpose of the project?}

AMIS was meant to provide Finance with direct financial control over asset tracking/ purchase/value at all breakdown levels (individual asset, station, district, region, and national). More broadly, the standardised asset processes would integrate electronically with other organisational processes as part of the overall ERP system, which enable better strategic planning and improve high-level reporting to Government. Again, there was a difference between this official HO perspective and the station perspective, who apparently assumed that the purpose was to reduce costs by rationalising the distribution of assets based on (HO's) perceived need. Given the historical bad feeling associated with HO initiated cost reduction, the stated purpose ought to have included an explicit assurance that this rationalisation was not the intention of HO. 


\subsubsection{Question 3: What ought to have been/was the measure of project success?}

The measures of success for the project as a whole were based on the traditional project parameters of budget, time, and functionality, including overall integration with the FMIS module. The asset data collection exercise, while included as part of the AMIS project, was seen as a sub-project with its own measures of success: all station managers signed off on their data provision, and the success measure was that the aggregated station-based data was expected to be 'acceptably' close (as decided by the AMIS PSC) to the national totals already possessed by Finance. Achieving this proved difficult. First, requiring station managers to sign off on the data they provided would only ensure success if they cared sufficiently about the accuracy, and many did not, particularly as the effort required to collect the station-level data was onerous. Second, the PSC had not agreed, prior to the audit, what level of aggregated totals would count as acceptable. Consequently, there was considerable debate within the PSC after each data collection round, and unanimity was never achieved. The QA Consultant consistently advised the PSC to agree on acceptable levels prior to each audit round. Further, he urged the PSC to treat the asset audit as an independent project, with a different project manager and separate resources, so that the AMIS project did not fall further and further behind in both budget and schedule. This advice was not taken.

\subsection{Sources of Control}

\subsubsection{Question 4: Who ought to have been/was the decision-maker that controlled the conditions for project success?}

The authority structures were centred on HO, the PSC, and the Project Manager. The measures of success for the AMIS project were set by the Executive Team at HO, but ongoing decisionmaking as to how 'success', based on these measures, was to be achieved was delegated to the PSC. The project manager was responsible for operational decision-making regarding the project team and working with the Vendor, but only within the decision-making framework provided by the PSC (the project activities were evaluated by the PSC through regular project reporting). Thus, project control was exerted both directly (through decision-making) and indirectly (through governance arrangements) by the HO/Finance dominated PSC: "...when you see the make-up of the senior management team, it's weighted towards the people who manage the business at National Office." [Vendor Consultant]. However, the AMIS project in general, and the audit sub-project in particular, required direct involvement from frontline staff at the station level. But, as demonstrated 10 years earlier, the frontline staff had the power to resist and overturn directives from HO. There were no mechanisms available to resolve the conflict over the audit process, and so the situation was handled on an ad hoc basis. After the second round of data collection still failed to satisfy the PSC, the issue was briefly escalated to the CEO, who asked all regional managers to enforce co-operation from station managers. This did not, apparently, appreciably improve the situation: “...[and the stations] were like separate governments. ...[they were commanded to cooperate]... . But then [they responded]...'No, you aren't coming onto my patch'...'We do it this way' or 'We do it differently'... lot of that sort of talk [ensued]." [Vendor Consultant]

\subsubsection{Question 5: What resources ought to have been/were controlled by the decision-maker?}

The PSC had full control of the resources (via the budget) allocated by the Executive Team for the project, who hired the relevant staff, paid for vendor involvement, etc. The project manager had control of the operational resources, within the constraints set by the PSC. The project manager was also meant to have control over access to the assets, but was unable to achieve this, and this was one of the primary reasons for her removal. However, escalation to higher authorities did not improve matters. Given how onerous the actual audit was for the stations, it could be argued that they should have been provided with additional resources to help although it is not clear what these additional resources could have been, because the audit required specialist knowledge and skills held by a limited pool of professionals. 


\subsubsection{Question 6: What resources ought to have been/were outside the control of the decision-maker?}

The organisation owned the assets, and Finance was responsible for their financial management. However, the assets were physically resident in the stations and under direct control of the station managers. Further, the station staff had the knowledge, expertise and labour required to conduct the asset audit effectively. For these reasons, it could be argued that the physical control of the assets should remain outside the control of the Finance-dominated PSC.

\subsection{Sources of Knowledge / Expertise}

\subsubsection{Question 7: Who ought to have/did provide the relevant knowledge and skills?}

Most of the necessary skills and knowledge were provided through the PSC and project team: the Vendor and IT Dept provided software development and implementation; the Finance Dept. provided financial asset management; the AMIS project manager, project management; and the $Q A$ Consultant, independent quality assurance of project-related practices. Nevertheless, there were three areas of concern. The first was a relative lack of experience with major, complex IT projects. Until the decision to implement an ERP system had been made, IT-related change had mostly been on a smaller scale. The QA consultant had the requisite experience and had offered advice regarding the separation of the asset audit as an independent project and the agreement on what constituted satisfactory audit data - but this advice was not heeded. Second, the original project manager was made responsible for gaining cooperation from frontline staff, but did not seem to possess the ability to do so. Two interviewees suggested that being female, she may have found it difficult to achieve rapport in a very 'blokey', male-dominated culture. Another problem was that she, as a contractor, was seen as an outsider. Third, as the need to co-opt experience with frontline work into the PSC demonstrated, the relevant knowledge about the physical assets was not initially available: "There was not a great communication line to tell people what they were doing, to encourage them to help, and so the data [the collection team] brought back was, frankly, compromised." [Regional Manager]

\subsubsection{Question 8: What ought to have been/were the necessary knowledge and skills?}

As noted above, most of the requisite skills and knowledge to successfully complete an IT project were available. However, there was a failure of the PSC to recognise the need for the asset knowledge and asset handling skills possessed by the frontline staff. There was also, it seems, a failure to recognise the value of experience with large IT projects, as offered by the QA Consultant.

\subsubsection{Question 9: What ought to have been/were regarded as assurances of successful implementation?}

The PSC were responsible for monitoring and agreeing upon the budgetary and scheduling objectives, with the help of the QA Consultant. The CFO and other members of Finance were responsible for ensuring the required level of financial asset management functionality was achieved. It was not clear, from the data collected, who was responsible for the equivalent physical asset management functionality. Given the initially poor classification system design provided by Finance, it is possible they were initially the primary arbiters of success for the asset audit, before this role eventually fell to the PSC. In spite of possessing the greatest knowledge about physical asset management on the PSC, the co-opted Regional Manager arguably ought to have had a major role, but his experience was not harnessed.

\subsection{Sources of Legitimation}

\subsubsection{Question 10: Who ought to have been/was representing the interests of those negatively affected by, but not involved with the project?}

Frontline staff were negatively affected, first, by being required to invest considerable time and effort into the asset audit, and second by losing much of the control they had over their own 
asset management. They were not provided with representation in either the governance or management bodies regarding key decisions relating to the design of the system and the conduct of the project. Although they were involved with the project, this consisted primarily of being told what to do, with little apparent consultation.

It can be argued that with representation on the PSC, frontline staff would have had greater, likely positive, influence on the events that caused project delays. Although co-opted onto the PSC for different reasons, the Regional Manager did at least try to explain the station-level perspective, but with limited success. Furthermore, because a regional manager is relatively high in the authority hierarchy, the frontline staff may have preferred someone closer to their level and correspondingly further from $\mathrm{HO}$.

\subsubsection{Question 11: What ought to have been/were the opportunities for the interests of those negatively affected to have expression and freedom from the worldview of the project?}

HO, especially through their representation on the PSC, held virtually all legitimacy. Emancipation for frontline staff did not occur. As problems with the audit ensued, the PSC were aware the frontline staff were unhappy, yet still assumed that coercion, as opposed to consultation, was the answer: "When it was brought to their attention that they had an issue, [the PSC] tried to do everything that needed to be done to bring it back on track. But that was based on a misunderstanding about just how difficult it was. The issue was essentially allowed to drag on." [QA Advisor]. "Everything that needed to be done" did not include the PSC recognizing the structural conflict and the underlying marginalisation of a major stakeholder group. If anything, their attempts at resolving the issue appeared to further entrench the conflict.

\subsubsection{Question 12: What space ought to have been/was available for reconciling differing worldviews regarding the project among those involved and affected?}

HO-based interviewees suggested frontline staff were seen by $\mathrm{HO}$ as resistant to change, and many of them computer illiterate. It was assumed that, in a command-and-control environment, operational staff would do what they were told. Frontline staff had a worldview based on safety, public service and autonomy at the station level; they saw AMIS as interfering with that autonomy and forcing them to adopt a system devised by HO.

The worldview of HO was managerial and militaristic; it privileged the agenda of the head office managers, and adopted a militaristic command-and-control approach towards frontline staff. The worldview ought to have recognised the dependence of the project on the professional expertise and co-operation of frontline staff and adopted a more consultative approach.

\subsection{Boundary Critique}

As both Midgley (1992) and Ulrich (2000) point out, boundary setting is a general cognitive prerequisite for identifying a system of interest to the respective decision-makers. The frontline community were not represented in the governance structure for the project. In fact, until the regional manager was co-opted, the PSC did not include anyone who had ever been involved in frontline operations. Establishing governance structures is an explicit boundary setting process. It establishes decision-making rights - frontline staff were not part of the decision-making as to how assets would be coded or data would be captured. It legitimises some stakeholders and their value systems - by controlling the governance processes, HO (and particularly Finance) legitimised their values and world-view. In the minds of the decisionmakers, the frontline staff were 'outside' the authority and decision-making structures. The boundary decision, and the value conflicts embedded in the project governance structure, are shown in Figure 2.

The value conflicts over asset management were considerable, and understandable when the respective roles of the two groups were considered. Frontline staff were extremely engaged with the operational maintenance of their assets, keeping them work-ready, safe, and in good 
order. They were also very engaged in the correct, professional use of highly specialised and very expensive equipment. Lives, literally, depended on this. They were much less concerned with ensuring that the assets were accurately described in a system that added no value to the day-to-day conduct of their work, and they did not need a system to remind them to maintain or replace their assets; their safe use was motivation enough.

Head office representatives, by comparison, did not have the visceral involvement with equipment that frontline staff did, and would probably never be able to fully understand this worldview. Their worldview was based on the responsible financial management of a large asset pool. A boundary critique suggests that some level of values conflict was almost inevitable.

\subsubsection{Entrenched Structural Conflict}

We can see in Figure 2 that the establishment of governance structures created real boundaries that reflected the cognitive boundaries, value conflicts, and different worldviews of people involved in the project. However, theorists of boundary conflicts suggest that these conflicts can have impacts beyond the boundaries of the immediate situation and life-span of the system (or project) being considered. If the value conflicts are not recognised and addressed, they can 'stabilise' and perpetuate over longer periods of time, so that although immediate conflict situations may be resolved, divisions between stakeholder groups can continue for an extended period, generating further instances of conflict (Midgley \& Pinzon, 2011). This structural conflict, also known as relationship or affective conflict, "...is detrimental to individual and group performance, member satisfaction, and the likelihood a group will work together in the future." (Jehn \& Mannix, 2001, p.239). A major insight from applying the boundary critique approach to the case study was the identification of entrenched structural conflict between stations and $\mathrm{HO}$ which arose from the previous history of intense conflict between $\mathrm{HO}$ and stations over assets. While the AMIS project was seen by $\mathrm{HO}$ as a continuation of the phased ERP implementation, participants pointed out that the issue of asset management was organisationally sensitive for historical reasons. This conflict was resistant to regular forms of communication, and was sufficiently entrenched that the good efforts of individuals had no impact: "You tell them there is no sinister, hidden purpose ... we're not trying to take your assets. We're just trying to get a fair reflection of what they actually are. Then everyone delves back into the past, and their memories are [long].... So there is that general mistrust." [National Finance Manager]. This mistrust highlighted just how different the worldview of the frontline staff was: "[This was] because the people out there think these people in [HO], in the main, they're just a bunch of selfish idiots... particularly because they wear a suit - they don't wear a uniform." [Regional Manager]. The project was starting with an atmosphere of mistrust, suspicion, and entrenched structural conflict between two major stakeholder groups which was not recognized or addressed.

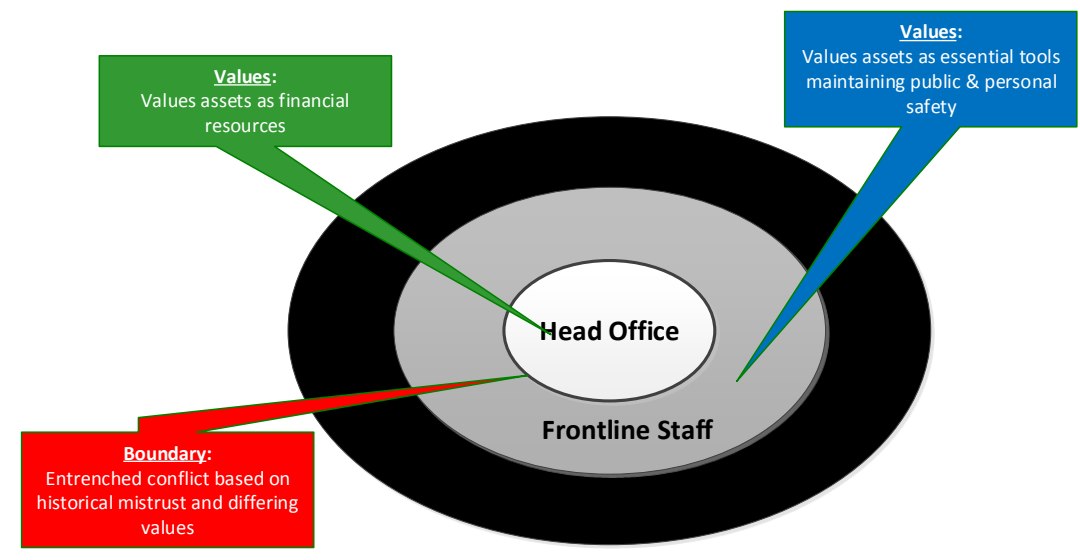

Figure 2. Marginalisation of frontline staff by the Executive Team 


\section{Discussion}

In this section, we discuss the implications of our application of CSH principles and boundary critique in the context of our wider research questions. We recall these were: RQ1) What insights can $\mathrm{CSH}$, as a diagnostic tool, contribute to our understanding of IT project governance in this case study? And RQ2) How can CSH be used effectively as a tool for improving IT project governance?

Earlier, IT project governance was defined as a set of arrangements based around three components: the allocation of decision-making authority, establishing rights and responsibilities; the creation of relevant policies that constrain and guide decision-makers; and the establishment of mechanisms, such as processes, procedures and methodologies that can be used by decision-makers as aids to the conduct of the project.

\subsection{Descriptive mapping of the case}

We address RQ1 by examining the 'descriptive mapping' of the case situation, based on the diagnostic 'was' analysis of the 12 questions. There were two levels of ITPG in operation. At the project level, the PSC had allocated operational decision-making authority to the project manager, had policies in place constraining and guiding her decisions regarding allocation of resources, frequency of reporting, working with the project team (including those from both the IT Department and the Vendor), and provided mechanisms for reporting on progress, including budget, schedule and functionality measures. However, problems arose when issues that could not readily be resolved by the project manager (especially regarding working relationships with frontline staff) were escalated to the PSC. It was then that the PSC were acting as decision-makers within the higher level governance framework established by the Executive Team.

At the higher level, the Executive Team allocated decision-making authority to a PSC almost exclusively comprised of HO personnel, with a strong bias towards Finance, who were seen as the main beneficiaries of the new system. The lack of clear policy on how to deal with issues affecting the project only emphasised the lack of experience the PSC membership had with larger, more complex IT projects, and their tendency to act on an ad hoc basis. Furthermore, no formal mechanisms for consultation and communication with frontline staff were available.

Thus, while it can be argued that the PSC were making many of the mistakes, the root problems appear to go back to the governance at the organisational level. The Executive Team allocated authority to a committee in its own likeness, disregarding (albeit unconsciously) the cultural gap ("suits" vs. "uniforms") and entrenched conflict between HO and the front line. The CSH questioning highlighted the dominance of $\mathrm{HO}$ in terms of system benefits, control and knowledge recognition, and the lack of legitimacy held by those at the lower end of the command-and-control hierarchy.

\subsection{Ideal mapping of the case}

We address RQ2 by examining the 'ideal mapping' of the case situation, based on the 'ought' analysis of the 12 questions. Here we present an alternative narrative for the project, as it might have unfolded if the governance were configured differently. The purpose is to extrapolate the likely implications of a more balanced and inclusive governance structure; to derive insights for this case, and for the design of IT project governance arrangements in general.

It was argued that many of the problems experienced in AMIS, while exacerbated by some of the decision-making by the PSC, could ultimately be traced back to the governance at the organisational level. CSH revealed the failure to identify, respect and legitimise an important stakeholder by the Executive Team, instead ensuring project level governance continued to reflect the worldview and values of HO. Allocating decision-making authority to a stakeholder representative body like a project steering committee needs to be fully representative, not only to be fair, but to help prevent, mitigate or resolve damaging conflict. 
Organisational ITPG could also include mechanisms (including the project methodology), and policies requiring their use, to: enable open, consultative communication channels with affected parties; ensure sources of knowledge and skills are both recognised and utilised; resources are allocated to those that need them to do their jobs (beyond the needs of HO); and, importantly, formally recognise and address conflict between stakeholders. As Midgley and Pinzon (2011) note, "a good participative process can often support people in exploring their differences without them ever experiencing this as a conflict.” (p.1545).

One of our contributions is to demonstrate that IT project governance is inherently and by its nature a boundary-setting exercise. If we understand it as such, and apply a CSH lens, we see that establishing and applying IT project governance frameworks can never be value neutral but will always contain embedded worldviews. In the vast majority of cases, these are those of the system sponsor. Dissenting stakeholders are seen as a problem to be overcome, not as legitimate proponents of alternative world-views and value-systems. Marginalisation or hostility towards some project stakeholders can be understood as a direct outcome of the worldview of those who put IT project governance arrangements in place. Since frontline staff were professionally, intimately involved with the physical assets they used, the HO worldview also needed to account for the expertise and knowledge they possessed, and the benefits that should accrue for their direct involvement with the project. Rather than attempting to move control of the assets to higher levels of decision-making, the controllers of the assets should have been moved to higher levels of decision-making. This raises the issue of coercion - if there is a power imbalance, how can CSH help if the powerful simply close debate? In the case discussed here, the power imbalance was evident with a strong command-and-control culture; an expectation that frontline staff will simply do what they are told. But the affected were involved in this case, and they did have (or find) the power to negatively impact the project. By creating a policy requiring full identification and representation of stakeholders when membership of a steering group is being established destabilising conflict can be prevented. While this provides no guarantee of an emancipation, even where stakeholders may genuinely be powerless and affected but not involved, policy supporting their involvement in high-level decision-making may still lead to a better outcome.

Another contribution is the observation, through boundary critique, that conflict can become entrenched over time, if the marginalisation through differing worldviews is not addressed. In this case, the marginalisation occurred in a dramatic fashion ten years earlier, and distrust of HO by frontline staff had remained ever since. While projects may be temporary structures, in many organisations, business and social situations, the same stakeholder groups are required to interact over periods of time that may extend over decades. This could easily apply in other situations: operational staff and management; professional groups, like teachers and doctors, and the government agencies that fund them; welfare clients and welfare providers; telecommunications users and telecommunications companies.

A mechanism for conflict resolution (for example, an issue register) will likely only address the symptoms of structural conflict, not its underlying cause. Those responsible for project oversight should be encouraged to think in broader terms, including the potential for marginalisation and the role of the organisational machinery in perpetuating these boundary mismatches and the continued risk of conflict. Unlike other types of organisational conflict, structural conflict can be harder to eradicate and potentially more damaging over the long term (Jehn \& Mannix, 2001).

Finally, there is the question as to how CSH can be used in the future to improve IT project governance. The CSH questions were described by their originator as a "framework for reflective practice based on practical philosophy and systems thinking. ${ }^{\text {" }}$ " Ulrich emphasises that the CSH approach is not only intended as a critical method. "Despite its emancipatory implications (the aspect for which it is best known), CSH should not be misunderstood and used as an emancipatory systems approach only; for its principle of systematic boundary

3 http://wulrich.com/csh.html 
critique is vital for sound professional practice in general 4 ". The use of critical systems thinking techniques in IT projects has been rare (e.g. Cordoba \& Midgley, 2008). We believe the CSH approach can make multiple contributions to IT project governance. First, as a governance design tool. Establishing high-level IT project governance has a critical role in addressing potential conflicts in worldviews, before projects begin. The CSH questions are clear, intuitive and usable by practitioners designing IT project governance structures. This includes appointing fully representative steering committees, adopting appropriate policies that guide and constrain decision-making, and providing inclusive, consultative processes and methodologies that can help prevent, mitigate or reduce conflict. Second, as a diagnostic tool, for remediating at-risk projects or as part of a post-implementation review, particularly where stakeholder conflict may have occurred. Finally to understand projects in a wider organizational context, identify entrenched structural conflicts that may cause recurring problems in projects, and put governance mechanisms in place to address them.

\section{Further Research}

One of the leading project management frameworks, the PMBOK, did not introduce a dedicated section on stakeholders until its 5 th edition, and the leading IT service management framework, ITIL, does not include any specific knowledge area for stakeholder management. While stakeholders are better represented in TOGAF, the type of questions asked by Midgley and Ulrich are entirely absent in frameworks like PM-BOK, PRINCE2 and ITIL, which tend to focus instead on 'controlling' stakeholders. Further research could investigate how a critical examination of project boundaries and stakeholder expertise, legitimacy and authority could be incorporated effectively into leading industry methodologies and best practice frameworks.

\section{Limitations}

A major limitation of this study is it was conducted post-hoc on previously collected case data. In some respects this lends legitimacy to the results, as we did not start with an a priori assumption that there were issues with stakeholder boundaries, inclusion, authority and legitimacy, and these findings rather emerged from the data and a post-hoc literature search. In other respects, this is a limitation, as we were not able to fully explore these issues through further questioning. For example, no frontline staff were directly interviewed, although insights into their perspective were provided by the Regional Manager (as an ex-frontline officer), and the QA Consultant (as an independent observer).

\section{Conclusions}

In this paper, we argue that by: (i) incorporating a critical perspective in our conceptualisations of what IT project governance involves; and (ii) using a critical systems heuristics (CSH) lens for developing, implementing and reviewing governance arrangements, we can improve the effectiveness of IT governance arrangements in practice and reduce conflicts between stakeholder groups. We exhort IT professionals and managers to engage critically and constructively with the opportunities offered by different worldviews and marginalised constituencies; and to adopt the credo of "nothing about us without us", rather than seeing differences in perspective from different stakeholder groups as something that IT projects need to 'manage' and 'control'.

\section{References}

Almutairi, A., Gardner, G., \& McCarthy, A. (2014). Practical guidance for the use of pattern matching technique in case study research: A case presentation. Nursing and Health Sciences, 16(2), 239-244. 
Bekker, M. (2014). Project governance:" schools of thought. South African Journal of Economic and Management Sciences, 17(1), 22-32.

Biesenthal, C., \& Wilden, R. (2014). Multi-level project governance: Trends and opportunities. International Journal of Project Management, 32, 1291-1308.

Campbell, D. (1966). Pattern Matching as an essential in distal knowing. In K. R. Hammond (Ed.), The psychology of egon Brusnvick (pp. 81-106). New York: Holt, Rinchart, and Winston.

Churchman, C. (1970). Operations research as a profession. Management Science, 17(2), b37b53.

Cordoba, J., \& Midgley, G. (2008). Beyond organisational agendas: using boundary critique to facilitate the inclusion of societal concerns in information systems planning. European Journal of Information Systems, 17, 125-142.

Davis, K. (2014). Different stakeholder groups and their perceptions of project success. International Journal of Project Management, 32(2), 189-201.

Eisenhardt, K. (1989). Building Theories from Case Research. Academy of Management Review, 14(4), 532-550.

Evers, C., \& Echo, H. (2006). On generalizing from single case studies: Epistemological reflections. Journal of Philosophy in Education, 4O(4), 511-526.

Freeman, R. (1984). Strategic Management: A Stakeholder Approach. Boston, USA: Pitman.

Hammer, M. (1997). Beyond Reengineering: How the Process-Centered Organization Is Changing Our Work and Our Lives Harper Collins.

Jackson, M. (2003). Systems Thinking: Creative Holism for Managers. Chichester, UK: Wiley.

Jehn, K., \& Mannix, E. (2001). The dynamic nature of conflict: A longitudinal study of intragroup conflict and group performance. Academy of Management Journal 44(2), 238-251.

Jiang, J., Klein, G., \& Carr, C. (2002). Measuring Information Systems Service Quality: ServQual from the Other Side. MIS Quarterly, 26(2), 145.

Johnstone, D. (2010). IT project governance and stakeholder conflict resolution. PhD, Victoria University, Wellington.

Johnstone, D., Huff, S., \& Hope, B. (2006). IT projects: conflict, governance, and systems thinking. Paper presented at the Hawaii International Conference on Systems Sciences (HICSS), Hawaii.

Klakegg, O., Williams, T., Magnussen, O., \& Glasspool, H. (2008). Governance frameworks for public project development and estimation. [Klakegg, Ole Jonny, et al. "Governance frameworks for public project development and estimation." Project Management Journal 39.S1 (2008).]. Project Management Journal, 39(S1).

Kochan, T., \& Rubinstein, S. (2000). Toward a stakeholder theory of the firm: The Saturn partnership. Organization Science, 11(4), 367.

Kovács, G., \& Spens, K. (2005). Abductive reasoning in logistics research. International Journal of Physical Distribution \& Logistics Management 35(2), 132-144.

Midgley, G. (1992). The sacred and profane in critical systems thinking. Systemic Practice and Action Research Systemic Practice and Action Research, 5, 5-16.

Midgley, G. (1997). Dealing with coercion: Critical systems heuristics and beyond. Systems Practice, 10(1), 37-57. 
Midgley, G., \& Pinzon, L. (2011). Boundary critique and its implications for conflict prevention. Journal of the Operational Research Society, 62, 1543-1554.

Midgley, G., \& Richardson, K. (2007). Systems thinking for community involvement in policy analysis. Emergence: Complexity and Organization, 9(1/2), 167-183.

Mitchell, R., Agle, B., \& Wood, D. (1997). Toward a theory of stakeholder identification and salience: Defining the principle of who and what really counts. Academy of Management Review, 22(4), 853-887.

Muller, R. (2009). Project Governance (Fundamentals of project management): Ashgate Publishing Group.

Myers, M., \& Klein, H. (2011). A Set of Principles for Conducting Critical Research in Information Systems. MIS Quarterly, 35(1), 17-36.

Pinto, J. (2014). Project management, governance, and the normalization of deviance. International Journal of Project Management, 32(3), 376-387.

PMI. (2013). Guide to the Project Management Body of Knowledge (PM-BOK) (5th ed.): Project Management Institute.

Richet, J.-L., Ngwenyama, O., \& Rowe, F. (2016). Key stakeholders dissent and their influences in reframing of strategic intent in IS-enabled organizational transformation. Paper presented at the International Conference in Information Systems (ICIS), Dublin, Ireland.

Roberts, T., Cheney, P., \& Sweeney, P. (2002). Assessing group interaction during hands-on LAN projects. Engineering Management Journal 14(2), 13-19.

Too, E., \& Weaver, P. (2014). The management of project management: A conceptual framework for project governance. International Journal of Project Management, 32, 1382-1394.

Turner, J. (2009). The Handbook of Project-Based Management: Leading Strategic Change in Organizations: McGraw-Hill.

Ulrich, W. (1983). Critical Heuristics of Social Planning: A New Approach to Practical Philosophy. Chichester, UK: Wiley.

Ulrich, W. (1987). Critical heuristics of social systems design. European Journal of Operational Research, 31(3), 276-283.

Ulrich, W. (2000). Reflective practice in the civil society: the contribution of critically systemic thinking. Reflcetive Practice, 1(2), 247-268.

Ulrich, W. (2012). Operational research and critical systems thinking - an integrated perspective. Part 1: OR as applied systems thinking. Journal of the Operational Research Society, 63, 1228-1247.

Ulrich, W., \& Reynolds, M. (2010). Critical systems heuristics. In M. Reynolds \& S. Holwell (Eds.), Systems Approaches to Managing Change: A Practical Guide (pp. 243-292). London: Springer-Verlag.

Van Grembergen, W., \& De Haes, S. (2009). Enterprise Governance of Information Technology: Achieving Strategic Alignment and Value: Springer

Yin, R. (2013). Case Study Research: Design and Methods: Sage.

Copyright: (C) 2017 Johnstone \& Tate. This is an open-access article distributed under the terms of the Creative Commons Attribution-NonCommercial 3.0 Australia License, which 
permits non-commercial use, distribution, and reproduction in any medium, provided the original author and AJIS are credited.

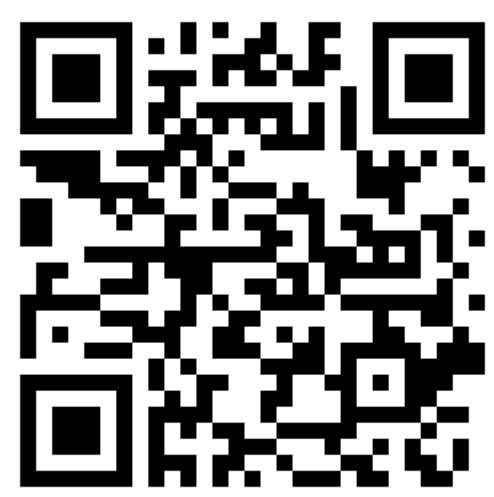

